Print ISSN: 2233-4165 / Online ISSN: 2233-5382

doi:http://dx.doi.org/10.13106/ijidb.2019.vol10.no7.39

\title{
Perceived Innovation Attributes and Acceptance of Chatbots as Determined by Consumer Characteristics*
}

\section{소비자 특성에 따른 챗봇의 인지된 혁신속성과 혁신수용}

\author{
Jaehwan JUNG(정재환) ${ }^{* *}$, Sangwoon BYUN(변상운) ${ }^{* * *}$, Mi-Sook $\mathrm{KIM}\left(\right.$ 김미숙) ${ }^{* * * *}$
}

Received: May 15, 2019. Revised: June 17, 2019. Accepted: July 05, 2019

\section{Abstract}

Purpose - The purpose of this study was to explore the impact of chatbots' innovation attributes on the innovation acceptance for consumers who have used chatbots to purchase fashion products that account for a large share of transactions in mobile shopping.

Research design, data, and methodology - Data were collected from Korean consumers aged 20 to 49 who had experience using chatbots when purchasing fashion-related products via mobile circumstances. After a pilot survey of 31 customers, pre-questionnaire was revised for the final test, and the final questionnaire was distributed to 1,500 subjects. Out of these, 244 were retrieved. After excluding 48 inappropriate responses, 196 were used for statistical analysis. Frequency analysis, exploratory factor analysis, one-way ANOVA, regression analysis and independent t-test using SPSS 23.0 were employed for data analyses.

Results - First, four factors of chatbots' attributes were extracted: relative advantages and compatibility, complexity, sensibility, and diversity. Second, two factors were extracted for fashion leadership: fashion opinion leadership and fashion innovativeness. Two groups based on the fashion leadership were identified: active innovation adopters and passive innovation adopters. Third, relative advantages and compatibility, diversity, sensibility of innovation attributes were found to have effects on the innovation acceptance in order. Fourth, significant differences were found in sensibility of innovation attributes and innovation acceptance in groups by marital status and age. The married in their 30s and 40s perceived sensibility as a more important attribute of chatbots than the unmarried in their twenties. Among the groups of different income levels, meaningful differences were found in diversity of innovation attributes and innovation acceptance. Fifth, there were significant differences found in relative advantages and compatibility, sensibility of innovation attributes, and acceptance of Innovation among the groups by fashion leadership. Active innovation adopters were found to be more aware of the importance of relative advantages and compatibility, and sensibility of innovation attributes, and innovation acceptance.

Conclusions - The present study provides chatbots' marketing strategies for fashion items need to be modified by demographic characteristics and fashion leadership. Particularly, fashion leadership was found to be an important factor in determining the perception of innovation attribute as well as innovation acceptance.

Keywords: Chatbots, Innovation Attributes, Fashion Leadership, Innovation Acceptance.

JEL Classifications: D91, L82, M31.

* This paper was modified and developed from the MA thesis of the first author.

** First Author, Master, Department of Clothing \& Textiles, Graduate School, Kyung Hee University, Korea.

*** Co-Author, Ph.D. Candidate, Department of Clothing \& Textiles, Graduate School, Kyung Hee University, Korea.

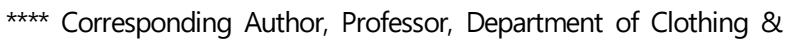
Textiles, Graduate School, Kyung Hee University, Korea. Tel: +82-2-961-0772, E-mail: mskim@khu.ac.kr

() Copyright: Korean Distribution Science Association (KODISA)
This is an Open Access article distributed under the terms of the Creative Commons Attribution Non-Commercial License (https://creativecommons.org/licenses/by-nc/4.0/) which permits unrestricted non-commercial use, distribution, and reproduction in any medium, provided the original work is properly cited. 


\section{1. 서론}

최근 스마트폰 기능향상과 모바일 온라인 접근성이 용이해 지면서 시간과 공간에 구애받지 않고 자유로이 정보탐색이 가 능해지고 있다(Han, 2018). 이에 따라 모바일 환경에서의 챗봇 (Chat-Bot) 서비스에 대한 관심이 증가하고 있다. 챗봇이란 '채 팅 로봇'의 줄임말로써, 인공지능(artificial intelligence)이 메신 저의 채팅창에서 대화하는 형식을 통해 소비자들이 필요로 하 는 정보를 제공하는 기능을 가진 소프트웨어이며(Choi \& Choi, 2017), 스마트 시대의 비즈니스 플랫폼을 선점하기 위해 다양한 기업들이 챗봇에 주목하고 있다(Min, Kim, \& Song, 2017).

인공지능과 같은 기술혁신이 기업을 성공으로 이끄는 가장 중요한 요인으로 인식되면서(Jung, Hwang, \& Song, 2015), IT 제품의 기술혁신은 매우 빠른 속도로 일어나고 있고 이에 대 한 소비 또한 매우 빠른 속도로 이루어지고 있다(Seo, 2015). 챗봇은 이러한 IT 제품의 특성에 따라 커뮤니케이션, 고객 관 계 관리, 커머스 등 다양한 방면에 빠르게 접목되고 있다. 텔 레그램, 카카오, 라인 등 모바일 메신저 플랫폼 사업자 이외에 도 구글, 텐센트, LG전자, 인터파크 등 국내외의 다양한 기업 들이 챗봇을 활용하고 있다. 이렇듯 국내외 ICT(Information and Communications Technologies)를 선도하는 기업들이 챗 봇을 운용하고 있으며, 소셜 커머스와 오픈 마켓에서 높은 매 출을 보이고 있는 패션분야에서도 챗봇이 활발하게 도입되고 있어 모바일 쇼핑 상황에서 챗봇을 직접 사용하고 있는 소비 자에 대한 연구가 필요한 실정이다. 더욱이 모바일 환경의 변 화에 의해 소비자들은 스마트 환경에서 보다 적극적인 정보와 의견 교환을 통해 타인의 의사결정에 지대한 영향을 주기도 한다(Stephen \& Lehmann, 2016). 그러므로 챗봇과 같은 혁신 기술은 서비스 초기에 타인에게 큰 영향력을 지닌 유행선도력 을 보유한 사용자를 확보하는 것이 중요할 것이다. 이와 더불 어 챗봇의 성공적인 확산을 위해서는 챗봇을 활용한 패션제품 구매경험자를 대상으로 한 연구가 필요할 것으로 판단된다.

따라서 본 연구는 모바일 환경에서 챗봇을 활용한 패션제품 구매경험을 보유한 소비자를 대상으로 챗봇의 혁신속성이 혁 신수용에 미치는 영향을 알아보고, 구매경험자의 인구통계적 특성과 유행선도력에 따른 챗봇의 인지된 혁신속성과 혁신수 용에는 어떠한 차이가 있는지에 규명하고자한다. 이와 같은 연 구를 통하여 이미 챗봇을 활용하고 있거나 앞으로 활용하고자 하는 기업들에게 필수적인 챗봇 이용자의 성향과 관련한 객관 적인 정보를 제공하고자 한다.

\section{2. 이론적 배경}

\section{1. 챗봇}

챗봇이란 이용자와의 대화를 통해 이용자가 원하는 정보를 찾아주는 인공지능 소프트웨어 기술을 말한다. 인공지능이 모 바일 메신저 플랫폼의 형식과 결합하여 인간처럼 대화를 나누 는 대화형 소프트웨어를 탑재하고 있는 것이다(Choi \& Choi, 2017). 즉, 챗봇은 모바일 메신저의 형태를 갖추고 있어서 필 요한 것이나 궁금한 것이 있으면 시간과 장소에 구애받지 않 고 메신저로 대화하듯 챗봇과 대화를 나누며 원하는 답을 얻
을 수 있는 1:1 자동화 대화형 플랫폼이다. 챗봇 운용 초기에 는 설정해둔 대답만을 제시할 수 있었으므로 이용자는 챗봇을 교류의 대상으로 여기지 않았으나, 최근에는 빅데이터, 딥러닝 등 방대한 데이터 및 인공지능학습 기술과 결합, 대화가 가능 한 수준으로 발전하여 이용자가 상호작용의 대상으로 인식하 게 되었다.

Hong, Cho, and Choi (2016)는 스마트홈 채팅인터페이스와 대화형 음성 인식 인터페이스의 의인화 수준에 따른 감성적 요인 및 향후 이용의도에 관한 연구를 실시하였는데, 연구 결 과 대화형 인터페이스는 의인화 수준을 높여야 사용자들의 지 속적인 이용의도를 기대할 수 있을 것으로 나타났으며, 채팅형 인터페이스의 경우 의인화 보다는 단축어, 선택메뉴, 그래픽 이미지 등을 활용하여 단축성과 상호작용의 효율성 등을 높이 는 방법이 더 효과적일 것이라는 실무적 솔루션을 제안하였다. Choi and Choi (2017)의 연구에서는 모바일 메신저 서비스 기 반의 인공지능 챗봇을 통한 제품의 주문 및 결제 서비스와 관 련된 인터페이스 요소 및 인터랙션 방식의 추출을 위해 심층 면접과 설문조사를 진행하고, 이에 더하여 챗봇 전문가를 대상 으로 심층 인터뷰를 병행하였다. 챗봇 인터페이스 사용자 조사 항목은 총 유용성, 검색성, 사용성, 감성성, 신뢰성으로 조사하 였고, 심층 면접 결과 챗봇과의 대화에서 사람처럼 느겨지는 감성성이 소비자들에게 중요하게 작용하는 것으로 나타났다. Park (2017)의 연구에서는 챗봇 서비스의 기술수용에 있어 인 지된 유희성이 챗봇 서비스의 인지된 유용성, 용이성을 매개했 을 때 소비자의 의도에 미치는 영향을 밝혔다. 연구 결과, 챗 봇 서비스의 용이성, 유용성에 인지된 유희성은 유의미한 영향 을 미치는 것으로 나타났다. 이러한 결과는 챗봇 서비스의 의 인화 및 감성성 측면이 챗봇 서비스의 성공여부를 가름하는 중요한 요인이 될 수 있다는 것을 나타낸다.

따라서 본 연구에서는 위와 같은 선행연구의 결과를 토대로 챗봇 특성에 후속변수로 감성성을 설정하여 혁신속성이 혁신 수용에 미치는 영향과 인구통계적 특성과 유행선도력에 따른 챗봇의 인지된 현신속성과 혁신수용의 차이를 규명하고자 하 였다.

\section{2. 혁신속성}

Rogers (1962)는 혁신을 잠재적 혁신 수용자들에게 새로운 것으로 인지되는 개념, 사물, 아이디어 등으로 정의하였고, Havelock (1969)은 혁신을 “지식의 활용과 확산”이라는 광범위 한 개념으로 정의하였다. Barnett (1953)는 혁신을 '마케팅 분 야의 혁신'과 '일반적인 혁신'의 두 가지로 분류하여 정의하였 는데, 마케팅 분야의 혁신은 목표 시장에서 이용이 가능하게 된 제품의 형태이며 잠재적 사용자들에게 새롭게 인식되어 다 르게 지각되는 특정 사물을 뜻한다고 하였으며, 일반적인 혁신 은 개인에게 다르고 새롭게 여겨지는 어떠한 사상, 행동, 사물 이라고 하였다.

혁신속성은 혁신을 구성하는 내부 속성을 의미하며 Rogers 는 지각된 혁신속성에 관한 이론적인 기틀을 제시하였다. Rogers and Shoemaker (1971)의 연구에서 혁신적 제품의 수 용을 촉진하는 혁신속성으로 소비자들이 느끼는 적합성 (compatibility), 복잡성(complexity), 상대적이점(relative advantage), 시험가능성(trialability), 관찰가능성(observability)의 5 가지 속성을 제시하였고, 이 다섯 가지의 속성은 소비자의 지각 정도에 따라 새로운 혁신제품을 수용하고 확산시키는 요 
인이라 하였다. 혁신에 관한 이론적 기틀이 정립된 이후, 다양 한 연구자들은 다섯 가지 혁신속성 요인을 연구분야와 연구주 제에 맞게 수정·보완하여 연구를 진행하였다.

Ostlund (1974)는 신제품의 인지된 혁신속성 연구에서 혁신 속성을 상대적이점, 적합성, 관찰가능성, 시험가능성, 복잡성에 지각된 위험을 추가로 설정으로 연구하였으며, Veryzer (1998) 는 혁신속성을 제품의 상대적 이점(product benefit), 기술우수 성(technical capability), 사용행태 변화(consumption pattern)의 세 가지 요인으로 분류하여 연구를 진행하였다.

Han, Kang, and Lee (2016)는 디자인 혁신속성의 척도에 대한 연구에서 고유성, 참신성, 창조성, 수용성의 네 요인으로 분류하여 연구한 결과, 유행에 흔들리지 않는 장기적 가치를 의미하는 고유성이 가장 중요한 요인이라 하였으며, Park (1999)은 패션 혁신행동에서 인지된 혁신속성을 유사성, 사회 적 상대적 이점, 기능적 상대적 이점, 인지된 위험으로 구분하 여 연구를 진행하였다. Yoo (2011)는 지능형 홈 네트워크에 관한 혁신속성 요인과 사용자의 혁신 수용 및 저항의 관계를 규명하였으며, 사용자의 지식수준 별 차이를 검증하였는데, 혁 신속성의 요인으로는 적합성, 상대적이점, 지각된 위험, 다양 성, 복잡성을 선정하여 검증하였다.

본 연구에서는 Rogers (1995)의 연구결과를 바탕으로 챗봇 의 혁신속성과 관련성이 있는 요인들을 재구성하여 챗봇의 혁 신속성으로 적합성, 상대적이점, 복잡성을 설정하고, $\mathrm{YoO}$ (2011)의 연구결과를 바탕으로 다양성을 추가설정 하였으며, Hong et al. (2016), Choi and Choi (2017), Park (2017)의 선 행연구에서 챗봇에서 유의미한 요인으로 나타난 감성성을 추 가로 설정하여 인구통계적 특성에 따른 챗봇의 혁신속성에 차 이가 있는지 알아보고자 한다.

\section{3. 혁신수용}

혁신성은 혁신의 정도를 이르는 개념으로 제품 및 소비자 모두에게 적용이 가능하며, 새로운 혁신제품 혹은 기술이 사회 에 소개될 때 마다 제기되었던 관심은 해당 제품과 기술이 얼 마나 빠르게 소비자들에게 채택되고 수용될 것이며, 그것으로 인해 소비자들의 이용행태는 또 얼마나 달라질 수 있을 것인 가 하는 것이다. Yoo (2011)의 연구에서는 혁신제품이 사회에 서 받아들여지거나 퇴출당하는 것은 혁신제품이 보유한 상대 적 이점을 인식하고 이를 채택하는 수용자에 의한 것이라고 하였다. 혁신제품을 소비자들이 인지하고 선택하도록 만드는 데 소비자의 혁신성이 중요한 역할을 한다고 Midgley and Dowling (1993)은 연구에서 밝혔다. 이처럼 소비자의 혁신성은 혁신제품과 기술의 확산과 인지되고 채택되는 과정에서 중요 한 영향을 미치는 속성으로 치열한 경쟁 속에 놓여있는 기업 들에게는 지속적으로 수익창출을 가능케 하는 역할을 하므로 더욱 더 강조되고 있다(Hirschman, 1980; Hoffmann \& Soyez, 2010). Jeong and $\mathrm{Kim}$ (2003)은 높은 혁신성을 가진 소비자 들과 낮은 혁신성을 가진 소비자들이 고려하는 제품군의 크기 와 구성에는 어떠한 차이가 있는지를 규명하였다. 연구 결과, 높은 혁신성향을 보유한 소비자는 제품 구매 시 다양한 경로 를 이용하고 있었으며, 낮은 혁신성향을 보유한 소비자는 제품 구매 시 한정된 구매 경로를 이용하고 있는 것으로 나타났다. 혁신수용은 혁신적인 제품이나 기술의 수용과정 또는 혁신과 관련된 의사를 결정하는 과정은 처음으로 혁신에 대해 인지하 며 태도를 형성하게 되고 혁신수용결정을 하게 되는 일련의
정신적인 과정이라고 할 수 있으며, 확산(diffusion)되는 과정은 혁신이 일정기간 동안 전체적인 시장에서 각각의 사회구성원 들에게 전달되는 것이라고 하였다(Rogers, 1995). 즉, 수용과 정과 확산과정을 구분하여 확산과정은 사회 구성원들끼리 혁 신적인 제품을 공유하며 교환이 이루어지는 것이고, 수용과정 은 혁신적인 제품을 사용하겠다는 개개인의 의사결정이라 하 였다. Lee (2017)는 모바일 간편 결제 서비스의 기능적 특성 이 사용자 만족도에 미치는 영향과 인구통계적 특성에 따른 만족도의 차이를 살펴보았는데 연구결과, 인구통계적 특성 중 연령에 따른 유의한 차이가 나타났으며, 연령이 낮아질수록 거 부감 없이 신기술을 수용하는 것으로 나타났다. Park and Park (2017)은 인터넷뱅킹의 이용경향을 조사하면서 UTAUT모 형과 정보격차이론을 이용하여 실제 인터넷뱅킹 이용자를 대 상으로 수용의도를 실증적으로 분석하였다. '소득수준은 촉진 조건, 노력기대, 인지된 위험에 정의 영향을 미칠 것이다'는 가 설이 부분적으로 지지되어 인터넷뱅킹 사용자들은 고소득 중 장년층 남성들이 주도적인 역할을 할 것이라는 연구결과가 나 타났다.

선행연구 고찰 결과, 인구통계적 특성을 이용하여 수용의도 를 살펴 본 연구들은 다양한 분야에서 진행되고 있지만, 챗봇 과 같은 혁신 기술의 수용의도 차이에 관한 연구는 부족한 실 정으로, 본 연구에서는 모바일 OS에서 메신저 플랫폼으로 급 격하게 변화하고 있는 챗봇을 소비자들의 기존의 행동 방식을 전환시킬 수 있는 혁신적인 제품으로 정의하고 인구통계적 특 성에 따른 챗봇의 혁신수용에 관한 소비자 간 차이를 알아보 고자 한다.

\section{4. 유행선도력}

유행선도력은 의류학 분야에서 주로 활용되고 연구되어 왔 으며 새로운 패션을 앞서서 받아들이고 영향을 주는 정도를 의미한다. Kaiser (1985)는 유행을 개인적 차별화의 욕구와 사 회적 공동화의 욕구인 두 가지 심리적 지주로 지탱되고, 일정 한 시기에 사회적으로 승인되어 지속적으로 변화할 것으로 기 대되는 집합적 행동의 한 형태라고 정의하였다. 본 연구에서는 유행선도력을 소비자 특성 중의 하나로 사용되었다.

Chung and Moon (2001)은 유행이 확산되는 과정 중 빠르 게 받아들여지거나, 구매의사결정과정 중 다른 소비자에게 미 치는 영향력을 유행선도력이라고 하였다. Yang (2005)의 연구 에서는 비공식적으로 강한 영향력을 보유한 소비자들을 유행 선도자라 하였으며, 의견선도력 및 유행혁신성과 관련이 깊다 고 하였다. Koh and Nam (1998)의 연구에서는 유행선도력을 유행혁신성과 의견선도력으로 분류하여 연구를 진행하였다. 의 류학 분야에서 유행선도력은 새로운 패션을 보다 빨리 받아들 이고 다른 이들에게 영향을 미치는 의미로 활용되어지고 연구 되어 왔다. 본 연구에서는 기술적인 혁신에 관련된 챗봇에 대 해 연구하는 것이므로 일반적인 혁신에 연관된 유행선도력과 의복과 연관된 유행선도력을 함께 살펴보고자 한다. Cho and Koh (2001)의 연구에서는 유행선도력에 따른 의복추구혜택 및 유행선택행동, 의복구매실태 특성의 차이를 살펴보았으며 차이 를 검증하기 위해 유행선도력에 따른 소비자 집단을 유행 혁 신성 및 의견선도력 집단으로 구분하여 측정하였다. $\mathrm{Kim}$ and Rhee (2001)는 쇼핑관련특성을 유행선도력을 통해 관계를 밝 히는 연구에서 유행선도력은 유행 의견선도력과 혁신성을 포 함하여 하나의 단일 차원으로 구성되어 있음을 밝혔다. 
이에 본 연구에서는 선행연구들을 바탕으로 유행선도력을 의견선도력과 혁신성 2가지 차원으로 측정하였으며, 혁신성이 강하며 의견선도력이 뛰어난 것을 유행선도력으로 정의하였다.

\section{5. 연구문제}

본 연구는 패션 관련 제품 모바일 쇼핑 시 챗봇을 이용해 본 경험이 있는 소비자들을 대상으로 혁신속성이 혁신 수용에 어떠한 영향을 미치는지 알아보자 하였다. 그리고 인구통계적 특성과 유행선도력을 포함하는 소비자 특성에 따라 인지된 혁 신속성과 혁신수용에 어떠한 차이가 있는지에 대해 알아보고 자 하였다.

\section{연구문제 1:}

챗봇의 인지된 혁신속성이 혁신수용에 영향을 미치는지 알 아본다.

\section{연구문제 2:}

소비자 특성에 따른 챗봇의 인지된 혁신속성의 차이를 알 아본다.

\section{연구문제 3:}

소비자 특성에 따른 챗봇의 인지된 혁신수용의 차이를 알 아본다. 같다.

이상의 연구문제를 그림으로 나타내면 다음의 연구모형과

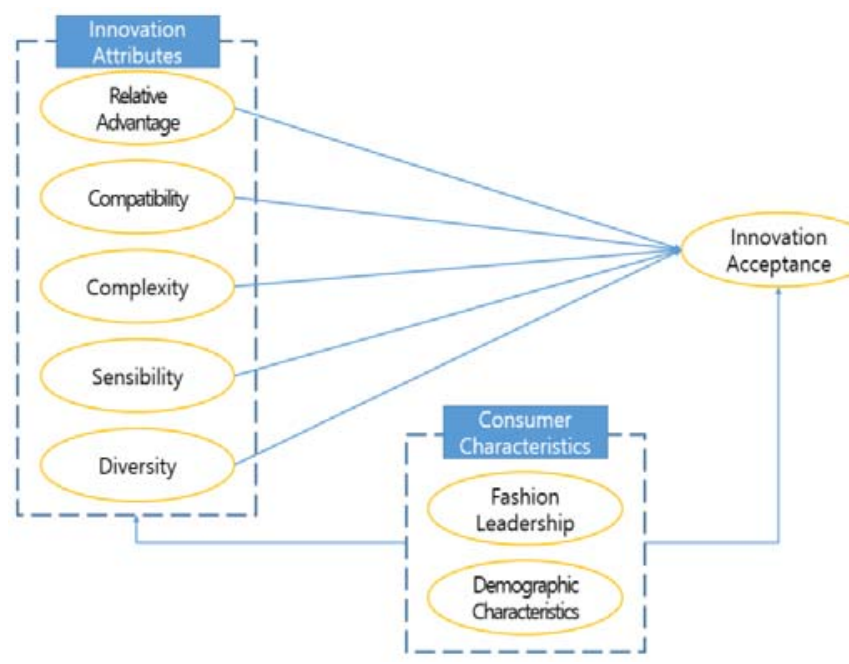

Figure 1: Research Model

\section{3. 연구방법}

\section{1. 연구설정 및 자료수집}

본 조사의 대상자들은 모바일 쇼핑 시 챗봇을 통해 패션관
련 제품 구매 경험이 있는 소비자들이어야 했기 때문에, 본 조 사 대상자들은 챗봇을 이용해 패션 관련 제품의 구매 경험이 있는 20대에서 40대 남, 녀를 대상으로 설문을 진행하였다.

31 명을 대상으로 사전조사 실시 후, 설문 타당성 검증을 실 시하였으며, 사전조사 후 설문지의 신뢰도 확인과정에서 신뢰 도가 낮은 문항 3 개를 삭제하였다.

본조사는 총 1,500 명에게 배부하였고, 이 중 챗봇을 통해 패션 관련 제품을 구매해 본 경험이 있다고 응답한 244명의 자료 중 불성실한 응답 48명을 제외한 196 명의 자료를 본 연 구에 사용하였다.

\section{2. 변수의 조작적 정의}

본 연구에서는 혁신속성을 모바일 쇼핑 시 챗봇을 사용하면 서 인지된 혁신속성이라고 정의하고, Yoo (2011), Jeong (2017), Shin (2013), Hong et al. (2016), Choi and Choi (2017)의 연구에서 사용된 변수들을 본 연구에 맞게 수정, 보 완하여 상대적 이점, 적합성, 복잡성, 다양성, 감성성의 5 가지 속성으로 구성하였다. 혁신수용은 $\mathrm{Kim}$ and $\mathrm{Kim}$ (2012)의 연구 에서 사용된 변수를, 유행선도력은 Choi (2003)의 연구에서 사 용된 변수를 차용하여 구성하였다.

상대적 이점은 '기존 검색 방식보다 빠른 정보획득이 가능 한 정도', 적합성은 '다양한 소비자들이 이용하기에 적합한 정 도', 복잡성은 '챗봇 사용 방법의 어려운 정도', 감성성은 '챗봇 의 대화체와 실제 사람의 대화체 간 유사성', 다양성은 '챗봇은 다양한 용도성', 혁신수용은 ‘챗봇 사용 추천의도'로 본 연구의 목적에 맞게 수정 및 보완하여 총 5 문항으로 구성하였다.

\section{3. 자료분석}

본 연구에서는 챗봇의 인지된 혁신속성과 혁신수용에 대한 인과관계 및 인구통계적 특성과 유행선도력을 포함하는 소비 자 특성에 따라 인지된 혁신속성과 혁신수용에 어떠한 차이가 있는지에 대해 연구하기 위해 탐색적 요인분석(exploratory factor analysis), 신뢰도 분석(reliability analysis), 군집분석 (cluster analysis), 회귀분석(regression analysis), 독립표본 t-test(independent samples t-test), 일원배치분산분석(ANOVA) 분석을 실시하였다.

\section{4. 연구결과}

\section{1. 분석대상 표본의 특성}

조사대상자의 인구통계적 특성은 <Table. 1>과 같다. 성별 비율은 남성 $42.3 \%(83$ 명)와 여성 $57.7 \%(113$ 명)로서 여성 소비 자가 많았고, 연령은 30 대 47.5\%(93명) 20 대가 27\%(53명), 40 대 $25.5 \%$ (50명)순으로 많았다. 응답자들의 월평균 소득은 200 만원 이상 300 만원 미만이 $24 \%(47$ 명), 300 만원 이상 400 만원 미만이 $18.9 \%(37$ 명), 100 만원 이상 200만원 미만이 16.3\%(32 명)를 차지하였으며 미혼자가 $51.5 \%(101$ 명)로 다수를 차지하 였다. 
Table 1: Demographic Characteristics of Respondents

\begin{tabular}{|c|c|c|c|}
\hline \multicolumn{2}{|c|}{ Demographic Properties } & Frequency & Percent(\%) \\
\hline \multirow{2}{*}{ Gender } & Male & 83 & 42.3 \\
\hline & Female & 113 & 57.7 \\
\hline \multirow{3}{*}{ Age } & $20-29$ & 53 & 27.0 \\
\hline & $30-39$ & 93 & 47.5 \\
\hline & $40-49$ & 50 & 25.5 \\
\hline \multirow{6}{*}{$\begin{array}{c}\text { Income } \\
(\forall)\end{array}$} & under $1 \mathrm{mil}$ & 24 & 12.2 \\
\hline & $1 \mathrm{mil}$ - under $2 \mathrm{mil}$ & 32 & 16.3 \\
\hline & $2 \mathrm{mil}-$ under $3 \mathrm{mil}$ & 47 & 24.0 \\
\hline & $3 \mathrm{mil}-$ under $4 \mathrm{mil}$ & 37 & 18.9 \\
\hline & $4 \mathrm{mil}$ - under $5 \mathrm{mil}$ & 28 & 14.3 \\
\hline & $5 \mathrm{mil}$ or more & 28 & 14.3 \\
\hline \multirow{2}{*}{$\begin{array}{l}\text { Marital } \\
\text { Status }\end{array}$} & single & 101 & 51.5 \\
\hline & married & 95 & 48.5 \\
\hline \multicolumn{2}{|r|}{ Total } & 196 & 100.0 \\
\hline
\end{tabular}

\section{2. 구성개념의 신뢰성 및 타당성 검토}

측정도구의 타당성을 검정하기 위해 주성분분석과 베리맥스 회전 방식을 이용하여 챗봇의 혁신속성에 대한 요인분석을 실
시한 결과, 상대적 이점 및 적합성, 감성성, 복잡성, 다양성의 4개 요인이 추출되었다<Table. 2>. 4개 요인의 요인적재값은 모두 .6이상이었고, 누적 설명력은 각각 $65.53 \%$ 로 나타나 설 문문항의 타당성을 확인하였다. 이 중에서 상대적 이점과 적합 성이 하나의 요인으로 추출된 결과는 챗봇을 이용해 패션제품 을 구매해 본 경험이 있는 소비자들이 챗봇의 상대적 이점과 챗봇의 적합성을 동일시 한 결과로 해석된다. 신뢰도분석은 Cronbach's $\alpha$ 계수를 이용한 내적 일관성 분석방법을 사용하였 으며, 혁신속성의 Cronbach's $\alpha$ 값은 상대적 이점 및 적합성 .847 , 복잡성 .872 , 감성성 .872 , 다양성 .738 로 내적 일관성이 확보 된 것으로 판단할 수 있었다.

혁신수용에 관한 요인분석 결과는 <Table. 3>과 같다. 요인 적재값은 모두 .8 이상이었으며, 혁신수용 요인의 설명력은 $72.53 \%$ 로 나타나 설문문항의 타당성을 확보하였고, Cronbach $\alpha$ 값은 .810으로 내적 일관성도 확보된 것으로 판단된다.

유행선도력에 대한 요인분석 결과는 <Table. 4>와 같다. 유 행 혁신성, 유행 의견선도력의 총 2개 요인이 추출되었으며 2 개 요인의 요인적재값은 모두 .7 이상이었고, 누적설명력은 $73.09 \%$ 로 나타나 설문문항의 타당성을 확인하였다. 유행선도 력의 Cronbach $\alpha$ 값은 유행혁신성 .842 , 유행 의견선도력 .855로 내적 일관성도 확보된 것으로 판단된다.

Table 2: Results of Factor Analysis and Reliability Test for Chatbots' Innovation Attributes

\begin{tabular}{|c|c|c|c|c|c|c|}
\hline \multicolumn{2}{|c|}{ Factor } & Items & $\begin{array}{l}\text { Factor } \\
\text { Loading }\end{array}$ & $\begin{array}{l}\text { Eigen } \\
\text { Value }\end{array}$ & $\begin{array}{c}\% \text { of } \\
\text { Variance }\end{array}$ & Cronbach's a \\
\hline \multirow{17}{*}{$\begin{array}{l}\text { Chatbots' } \\
\text { Innovation } \\
\text { Attributes }\end{array}$} & \multirow{6}{*}{$\begin{array}{c}\text { Relative } \\
\text { Advantages } \\
\text { and } \\
\text { Compatibility }\end{array}$} & $\begin{array}{l}\text { Chatbots are more useful than } \\
\text { existing search methods. }\end{array}$ & .759 & \multirow{6}{*}{3.40} & \multirow{6}{*}{19.98} & \multirow{6}{*}{.847} \\
\hline & & $\begin{array}{l}\text { Chatbots are more efficient than } \\
\text { existing search methods. }\end{array}$ & .727 & & & \\
\hline & & $\begin{array}{l}\text { Chatbots are convenient to } \\
\text { acquire information faster than } \\
\text { existing search methods }\end{array}$ & .740 & & & \\
\hline & & $\begin{array}{l}\text { Chatbots are suitable to satisfy } \\
\text { the needs of users. }\end{array}$ & .659 & & & \\
\hline & & $\begin{array}{c}\text { Chatbots provide appropriate } \\
\text { information. }\end{array}$ & .704 & & & \\
\hline & & $\begin{array}{l}\text { Chatbots are suitable for use by } \\
\text { a wide variety of consumers. }\end{array}$ & .661 & & & \\
\hline & & $\begin{array}{l}\text { It is difficult to grasp the } \\
\text { function of the chatbots. }\end{array}$ & .747 & & & \\
\hline & Complexity & $\begin{array}{l}\text { It takes a lot of effort to handle } \\
\text { chatbots skillfully. }\end{array}$ & .877 & 2.93 & 17.25 & .872 \\
\hline & & It is difficult to use chatbots. & .889 & & & \\
\hline & & $\begin{array}{l}\text { The process of using chatbots is } \\
\text { complicated. }\end{array}$ & .861 & & & \\
\hline & & $\begin{array}{l}\text { Chatbots' chat process gives a } \\
\text { feeling of talking to real people. }\end{array}$ & .773 & & & \\
\hline & Sensibility & $\begin{array}{c}\text { Chatbots' dialogue feels similar } \\
\text { to real people. }\end{array}$ & .834 & & & \\
\hline & Setisidinty & $\begin{array}{l}\text { Chatbots' tone gives a similar } \\
\text { impression to real people. }\end{array}$ & .758 & 2.18 & 16.36 & .872 \\
\hline & & $\begin{array}{l}\text { Chatbots give users } \\
\text { a human touch. }\end{array}$ & .743 & & & \\
\hline & & $\begin{array}{l}\text { Chatbots can be used for a } \\
\text { variety of purposes. }\end{array}$ & .828 & & & \\
\hline & Diversity & $\begin{array}{l}\text { Chatbots can be used in } \\
\text { various fields. }\end{array}$ & .793 & 2.03 & 11.93 & .738 \\
\hline & & $\begin{array}{l}\text { Chatbots have many functions } \\
\text { that can be use. }\end{array}$ & .711 & & & \\
\hline
\end{tabular}


Table 3: Results of Factor Analysis and Reliability Test for Chatbots' Innovation Acceptance

\begin{tabular}{|c|c|c|c|c|c|}
\hline Factor & Items & $\begin{array}{l}\text { Factor } \\
\text { Loading }\end{array}$ & $\begin{array}{l}\text { Eigen } \\
\text { Value }\end{array}$ & $\begin{array}{c}\% \text { of } \\
\text { Variance }\end{array}$ & Cronbach's $\alpha$ \\
\hline \multirow{3}{*}{$\begin{array}{l}\text { Chatbots' } \\
\text { Innovation } \\
\text { Acceptance }\end{array}$} & I will recommend using chatbots to others. & .871 & \multirow{3}{*}{2.176} & \multirow{3}{*}{72.53} & \multirow{3}{*}{.810} \\
\hline & I will continue to use chatbots. & .823 & & & \\
\hline & $\begin{array}{l}\text { I will talk positively about chatbots to } \\
\text { people around me. }\end{array}$ & .861 & & & \\
\hline
\end{tabular}

Table 4: Results of Factor Analysis and Reliability Test of Fashion Leadership

\begin{tabular}{|c|c|c|c|c|c|}
\hline Factor & Items & $\begin{array}{l}\text { Factor } \\
\text { Loading }\end{array}$ & $\begin{array}{l}\text { Eigen } \\
\text { Value }\end{array}$ & $\begin{array}{c}\% \text { of } \\
\text { Variance }\end{array}$ & Cronbach's $\alpha$ \\
\hline \multirow{4}{*}{$\begin{array}{c}\text { Fashion } \\
\text { Innovativeness }\end{array}$} & $\begin{array}{l}\text { I tend to try it before the people around me } \\
\text { when new technology is released. }\end{array}$ & .789 & \multirow{4}{*}{2.820} & \multirow{4}{*}{40.291} & \multirow{4}{*}{0.842} \\
\hline & $\begin{array}{l}\text { I tend to accept new technology faster than } \\
\text { others. }\end{array}$ & .807 & & & \\
\hline & I tend to be familiar with new technology. & .782 & & & \\
\hline & $\begin{array}{l}\text { I want to stand out from others by using } \\
\text { new technology first. }\end{array}$ & .723 & & & \\
\hline \multirow{3}{*}{$\begin{array}{l}\text { Fashion Opinion } \\
\text { Leadership }\end{array}$} & $\begin{array}{l}\text { I tend to post my opinion on internet bulletin } \\
\text { boards or blogs after using new technology. }\end{array}$ & .766 & \multirow{3}{*}{2.296} & \multirow{3}{*}{32.803} & \multirow{3}{*}{0.855} \\
\hline & $\begin{array}{l}\text { I tend to write down a review of the new } \\
\text { technology I have used. }\end{array}$ & .777 & & & \\
\hline & $\begin{array}{l}\text { I tend to answer questions posted on the } \\
\text { Internet bulletin board well. }\end{array}$ & .885 & & & \\
\hline
\end{tabular}

\section{3. 챗봇의 혁신속성이 혁신수용에 미치는 영향}

챗봇의 혁신속성이 혁신수용에 미치는 영향을 알아보기 위 해 회귀분석을 실시한 결과는 <Table $5>$ 와 같다.

상대적이점 및 적합성 $(\beta=.454, \mathrm{t}=7.269, \mathrm{p}<.001)$ 이 가장 유 의한 정(+)적 영향을 미치는 것으로 나타났으며, 감성성 $(\beta$ $=.273, \mathrm{t}=4.593, \mathrm{p}<.001)$, 다양성 $(\beta=.180, \mathrm{t}=3.340, \mathrm{p}<.01)$ 의 순 서로 정(+)적 영향을 미치는 것으로 밝혀졌다. 챗봇의 복잡성 은 혁신수용에 영향을 미치지 않는 것으로 나타났다.

Table 5: The Effect of Innovation Attributes on the Innovation Acceptance

\begin{tabular}{|c|c|c|c|c|c|}
\hline $\begin{array}{c}\text { Independent } \\
\text { Variable }\end{array}$ & $\mathbf{B}$ & $\boldsymbol{\beta}$ & $\mathbf{t}$ & $\mathbf{R}^{\mathbf{2}}$ & $\mathbf{F}$ \\
\hline (Constant) & .506 & & 2.102 & & \\
\hline $\begin{array}{c}\text { Relative } \\
\text { advantages } \\
\text { and } \\
\text { Compatibility }\end{array}$ & .495 & .454 & $7.269^{* * *}$ & \multirow{2}{*}{534} & \multirow{2}{*}{$56.790^{* * *}$} \\
\hline Complexity & -.063 & -.082 & -1.623 & & \\
\hline Sensibility & .249 & .273 & $4.593^{* * *}$ & & \\
\hline \multicolumn{7}{|c|}{ Diversity } & .194 & .180 & $3.340^{* *}$ & & \\
\hline${ }^{*} p<.05,{ }^{* *} p<.01,{ }^{* * *} p<.001$ & \\
\hline
\end{tabular}

\section{4. 유행선도력 요인을 이용한 군집분석}

유행선도력 집단에서 챗봇의 인지된 혁신속성과 혁신수용의
차이를 알아보고자 군집분석을 실시하였다<Table 6>. 군집분 석을 실시한 결과 각각 106 명, 90 명의 두 집단으로 구분되었 으며, 집단 1 은 유행 혁신성, 유행 의견선도력 모두 높게 나타 나 '적극적 혁신수용자'로 명명하였고, 집단 2는 유행 혁신성, 유행 의견선도력이 모두 낮게 나타나 '소극적 혁신수용자'로 명명하였다.

Table 6: Results of Cluster Analysis by Fashion Innovativeness and Fashion Opinion Leadership

\begin{tabular}{|c|c|c|c|}
\hline & $\begin{array}{c}\text { Cluster 1. } \\
\text { Active Fashion } \\
\text { Innovator } \\
\text { (N=106) }\end{array}$ & $\begin{array}{c}\text { Cluster 2. } \\
\text { Passive Fashion } \\
\text { Innovator } \\
\mathbf{( N = 9 0 )}\end{array}$ & F-value \\
\hline $\begin{array}{c}\text { Fashion } \\
\text { Innovativeness }\end{array}$ & 3.82 & 2.66 & $210.233^{* * *}$ \\
\hline $\begin{array}{c}\text { Fashion Opinion } \\
\text { Leadership }\end{array}$ & 3.69 & 2.22 & $288.863^{* * *}$ \\
\hline
\end{tabular}

4.5. 소비자 특성에 따른 인지된 혁신속성과 혁신수용

전체 응답자들의 평균을 내어 혁신속성에서 어떠한 속성을 가장 크게 인지하고 있는지 확인해 본 결과, 다양성, 상대적이 점 및 적합성, 감성성, 복잡성 순으로 인지하는 것으로 나타났 다.

성별에 따른 인지된 혁신속성의 차이를 검증하기 위해 독립 표본 t-test를 실시한 결과, 혁신속성에 관해서 남성과 여성의 경우 유의미한 차이가 나타나지 않았다. 이는 남성과 여성 모 두가 다양성, 상대적이점 및 적합성, 감성성, 복잡성에 대한 인지 정도가 높기 때문으로 사료된다. 
Table 7: Innovation Attributes and Acceptance as Determined by Consumer Characteristics

\begin{tabular}{|c|c|c|c|c|c|}
\hline $\begin{array}{l}\text { Consumer } \\
\text { Characteristics } \\
\text { Innovation Attributes } \\
\text { and Acceptance }\end{array}$ & Gender & Age & $\begin{array}{c}\text { Income } \\
\text { (W) }\end{array}$ & $\begin{array}{l}\text { Marital } \\
\text { Status }\end{array}$ & $\begin{array}{l}\text { Fashion Opinion } \\
\text { Leadership }\end{array}$ \\
\hline $\begin{array}{c}\text { Relative Advantages and } \\
\text { Compatibility }\end{array}$ & n.s & n.s & n.s & n.s & $\begin{array}{c}\text { ** } \\
\text { Passive } \\
<\text { Active }\end{array}$ \\
\hline Complexity & n.s & n.s & n.s & n.s & n.s \\
\hline Sensibility & n.s & $20 s<30 s \cdot 40 s$ & n.s & $\begin{array}{c}\text { ** } \\
\text { Single } \\
\text { <Married }\end{array}$ & $\begin{array}{c}\quad * * * \\
\text { Passive } \\
<\text { Active }\end{array}$ \\
\hline Diversity & n.s & n.s & \begin{tabular}{l}
\multicolumn{2}{c}{$*$} \\
Under 5 mil. \\
<Over 5 mil.
\end{tabular} & n.s & n.s \\
\hline $\begin{array}{l}\text { Innovation } \\
\text { Acceptance }\end{array}$ & n.s & $30 s<40 s$ & $\begin{array}{l}\text { ** } \\
\text { Under } 5 \text { mil. } \\
\text { <Over } 5 \text { mil. }\end{array}$ & $\begin{array}{c}{ }^{*} \\
\text { Single } \\
<\text { Married }\end{array}$ & $\begin{array}{l}\quad * * * \\
\text { Passive } \\
<\text { Active }\end{array}$ \\
\hline
\end{tabular}

연령과 소득에 따른 인지된 혁신속성의 차이를 알아보기 위 해 일원배치분산분석(ANOVA)을 실시한 결과, 연령에 따라 감 성성에서 유의한 차이가 나타났다. 사후검증 결과 20 대와 30 대 40 대 간에는 유의한 차이가 나타났으며, 30 대와 40 대 간에 는 유의한 차이가 나타나지 않아 30 대-40대가 20대에 비해 감 성성에 있어서 더 크게 인지하는 것으로 나타났다. 소득에 따 라 인지된 혁신속성은 다양성에서 유의한 차이가 나타났다. 사 후검증 결과 500 만원 이상을 버는 소득자는 100 만원 미만부 터 500만원 미만을 버는 구간의 소득자와 유의한 차이가 나타 났으며, 100 만원 미만에서부터 500만원 미만을 버는 구간의 소득자 사이에서는 유의한 차이가 나타나지 않아, 500 만원 이 상을 버는 고소득자가 다양성에 대해 더 크게 인지하는 것으 로 나타났다.

결혼 여부에 따른 인지된 혁신속성 차이를 알아보기 위해 t-test를 실시한 결과 감성성에 있어서 유의한 차이가 나타났 다. 기혼자가 미혼자보다 감성성 인지 정도가 높게 나타났다.

적극적 혁신수용자와 소극적 혁신수용자 간 혁신속성 인지 차이를 살펴본 결과, 상대적이점 및 적합성과 감성성에서 통계 적으로 유의한 차이가 나타났는데 적극적 혁신수용자가 소극 적 혁신수용자보다 상대적이점 및 적합성과 감성성에 대해 인 지하는 정도가 높게 나타났다.

소비자 특성에 따른 혁신수용의 차이는 성별에 있어서는 유 의한 차이가 나타나지 않았으며, 연령과 소득에 따른 혁신수용 차이를 알아본 결과 연령에 따라 혁신수용에 유의한 차이가 나타났다. 사후검증 한 결과 20대-30대 간에는 혁신수용에 유 의한 차이가 없었으며, 20대40대 간에도 혁신수용에 유의한 차이가 나타나지 않았다. 30대-40대 간에는 혁신수용에 있어서 유의한 차이가 나타났으며, 40대가 30대보다 혁신수용 정도가 더 높게 나타났다. 소득 수준에 따라 유의한 차이가 나타나 사 후검증을 실시한 결과, 500 만원 이상의 소득자와 100 만원 미
만부터 500 만원 미만의 소득자 간 유의한 차이가 나타났으며, 100 만원 미만부터 500 만원 미만의 소득자 사이에서는 유의한 차이가 나타나지 않아, 500 만원 이상의 소득자가 혁신수용 정 도가 높게 나타났다.

결혼 여부에 따른 유의한 차이가 나타났으며, 기혼자가 미 혼자보다 혁신수용 정도가 더 높게 나타났으며, 유행선도력에 있어서는 적극적 혁신수용자와 소극적 혁신수용자 간 혁신수 용에 유의한 차이가 나타났는데, 적극적 혁신수용자가 소극적 혁신수용자 보다 혁신수용 정도가 더 높게 나타났다<Table. 7>.

\section{5. 결론}

\section{1. 연구결과 요약 및 논의사항}

본 연구에서는 모바일 쇼핑 시 챗봇을 이용해 본 소비자들 을 대상으로 인지된 챗봇의 혁신속성과 혁신수용에 대한 영향 과 차이에 대해 연구하여 챗봇을 이미 활용하고 있거나 활용 을 계획 중인 기업에게 챗봇 이용자의 성향과 관련한 실용적 인 정보를 제공하고자 하였다. 이를 위해 본 연구에서는 조사 대상자를 성별, 연령, 소득, 유행선도력, 결혼유무의 5 가지 변 수로 분류하고 이에 따른 차이점을 조사하였으며, 혁신속성이 혁신수용에 영향을 미치는가를 분석하였다.

본 연구의 결과의 요약 및 논의사항은 다음과 같다.

첫째, 혁신속성은 상대적이점 및 적합성, 감성성, 다양성의 순서로 혁신수용에 영향을 미치는 것으로 분석되었다. 복잡성 이 혁신수용에 영향을 못 미치는 것으로 나타난 원인은 앱을 다운 받아야 하는 귀찮은 방식이 아닌 기존에 사용하던 메신 저 플랫폼을 그대로 사용하는 등 소비자가 선호하는 서비스 
방식을 제공하고 있기 때문인 것으로 해석된다. 이러한 결과로 미루어 챗봇을 활용하는 기업들은 대중적인 메신저 플랫폼을 활용하여 서비스를 제공하는 노력이 필요할 것으로 판단된다.

둘째, 성별 차이를 살펴본 결과, 혁신속성과 혁신수용에서는 유의미한 차이가 나타나지 않았다. 이는 남성과 여성 모두 다 양성, 상대적이점 및 적합성, 감성성, 복잡성에 대해 높게 인 지하기 때문인 것으로 해석할 수 있다.

셋째, 연령에 따라서 인지된 혁신속성의 차이를 분석한 결 과 감성성에서만 유의한 차이가 나타났다. 혁신수용에서도 감 성성에 따른 유의한 차이가 나타났는데, 20대 젊은이들보다 30 대, 40대의 소비자 및 기혼자, 적극적 유행혁신자들이 감성 성을 중요시하는 것으로 나타났다. 이 같은 결과는 의인화 즉, 챗봇이 사용자에게 인간적인 감성을 느끼게 하는 정도, 챗봇의 어투나 어조가 실제 사람과 대화하는 느낌을 주는지를 중요시 하는 것으로 볼 수 있다.

넷째, 소득에 따른 인지된 혁신속성의 차이를 살펴본 결과 다양성에서만 소득수준에 따른 유의한 차이가 나타났으며, 혁 신수용에서도 소득수준에 따른 유의한 차이가 나타났다. 다양 성과 혁신수용 모두 500 만원 이상의 최상위 소득자가 500 만 원 미만의 소득자에 비해 높은 결과값을 보여 챗봇의 혁신성 과 다양한 서비스는 고소득자에게 중요하게 인지되는 것으로 나타나 고소득자들을 대상으로 하는 마케팅 전략 수립이 필요 할 것으로 보인다.

다섯째, 유행선도력에 따른 인지된 혁신속성의 차이를 살펴 본 결과 상대적이점 및 적합성, 감성성에서 유의한 차이가 발 생했으며, 혁신수용 또한 유의한 차이가 발생했다. 적극적 유행 혁신자가 혁신속성과 혁신수용 모두를 더 크게 인지하는 것으 로 나타난 결과를 보여, 적극적으로 혁신을 받아들이는 소비자 들을 대상으로 한 마케팅전략 수립이 유리할 것으로 판단된다.

챗봇 사용 시 기존 검색시스템보다 용이하고 유용한 정보를 제공하는지와 챗봇의 서비스가 소비자들의 욕구를 만족시킬 수 있는지가 적극적으로 혁신을 받아들이는 소비자들에게는 주요하게 받아들여지는 것으로 나타났다.

결론적으로 적극적인 혁신성향과 의견선도력을 가진 소비자 들에게 챗봇의 혁신속성 중 상대적이점 및 적합성이 중요하게 작용하는 것으로 나타나, 챗봇의 유저 인터페이스를 기존 검색 방식보다 유용하고 편리하게 제작하는 노력이 필요할 것으로 사료된다. 또한 단순히 많은 정보를 제공하는 것보다 정확한 정보를 제공하는 것이 필요할 것으로 사료된다.

\section{2. 연구의 시사점} 다.

본 연구의 연구결과를 바탕으로 살펴본 시사점은 다음과 같

혁신속성의 상대적이점 및 적합성은 적극적 혁신성향과 의 견선도력을 가진 소비자들에게서 유의하게 작용하는 것으로 나타나, 챗봇 사용 시 기존의 검색 방식과 비교하여 상대적으 로 유용성과 편리성을 느끼도록 하는 것이 필요하며, 많은 정 보를 제공하는 것보다 소비자들이 필요로 하는 적합하고 정확 한 정보를 제공하는 것이 필요할 것이다.

둘째, 혁신속성 중 복잡성은 모든 집단에서 차이가 나타나 지 않은 점은 기존에 사용하던 메신저 플랫폼을 이용하면서 소비자들이 불편함을 느끼지 않기 때문인 것으로 해석할 수 있다. 챗봇 사용 기업은 일반적인 메신저 플랫폼 형식을 사용 한 서비스 제공이 필요할 것이다.
셋째, 혁신속성 중 감성성은 30 대 이상의 기혼자 집단과 적 극적 혁신수용 집단에서 더 크게 인지하는 것으로 나타나, 챗 봇과 대화 시 챗봇의 대화체나 말투에서 인간적인 감성이 느 껴지도록 해야 할 것이다.

넷째, 고소득자 집단에서 혁신적인 기술의 활용성에 대해 더 크게 인지하는 것으로 나타나 기업에서는 고소득자를 주요 대상으로 하는 마케팅 전략 수립이 필요할 것이다.

다섯 째, 혁신수용은 40 대 이상 기혼자와 고소득자, 적극적 혁신수용자, 의견선도자 집단에서 더 크게 수용하며 지속사용 의도를 보이는 것으로 나타나, 챗봇과 같은 혁신 기술이 출시 되었을 때 이러한 소비자들을 대상으로 마케팅 전략을 세우는 것이 필요할 것이다.

\section{3. 연구의 한계 및 후속연구 제안}

본 연구의 제한점과 후속연구를 위한 제안사항을 정리하면 다음과 같다.

본 연구는 모바일 쇼핑 시 챗봇을 사용하여 패션제품을 구 매해 본 경험이 있는 소비자들로 편의 표집 된 표본을 사용하 였기 때문에 일반화에 주의가 필요할 것으로 사료되며, 모바일 쇼핑 이외의 다양한 분야에서도 챗봇이 사용되고 있기 때문에 다양한 분야의 챗봇 사용 사례에 대한 연구가 진행된다면 상 호 보완적 연구 결과를 얻을 수 있을 것으로 예상된다. 또한, 본 연구에서는 20대 40대 연령 집단을 대상으로 연구를 진행 하였으므로 보다 확장된 연령 집단을 대상으로 연구를 진행한 다면 실무적으로 보다 유익한 결과를 얻을 수 있을 것이다.

\section{References}

Stephen, A. T., \& Lehmann, D. R. (2016). How word-of-mouth transmission encouragement affects consumers' transmission decisions, receiver selection, and diffusion speed. International Journal of Research in Marketing, 33(4), 755-766.

Barnett, H. G. (1953). Innovation: The basis of cultural change. New York, NY: McGraw Hill.

Cho, Y. J., \& Koh, A. R. (2001). A Study on Psychological Characteristics and Clothing Benefits Sought According to Fashion Leadership. Journal of Consumer Studies, 12(3), 171-190.

Choi, S. M., \& Choi, Y. S. (2017). Analysis on the conversational commerce service interface of the $\mathrm{Al}$ Chat-Bot based on mobile messenger apps. Journal of the $\mathrm{HCl}$ Society of Korea, 2017(2), 237-240.

Choi, Y. Y. (2003). A Study of Cosmetics Purchase Behavior by Fashion Leadership of 20' women. (Master dissertation, Sookmyung University). Retrieved May 8, 2019 from http://dcollection.lib.sookmyung.ac.kr/public_ resource/pdf/000000006930_20190515113525.pdf

Chung, S. H., \& Moon, S. J. (2001). A Study on the Fashion Leadership and Wearing Attitude according to the Preference of Entertainers for Fashion Styles. Chung-Ang Journal of Human Ecology, 14, 163-186. 
Han, J. M., Kang, H, S,. \& Lee, M. A. (2016). Study on Scale Development of Design Innovation. Journal of Communication Design, (56), 366-378.

Han, S. S. (2018). Role of Online Social Decision When Purchasing NP: The Moderating Effect of NP Innovation. Journal of Distribution Science, 167), 57-65.

Havelock, R. G., \& Guskin, A. E. (1969). Planning for innovation: a comparative study of the literature on the dissemination and utilization of scientific knowledge. Center for Research on Utilization of Scientific Knowledge, University of Michigan.

Hirschman, E. C. (1980). Innovativeness, novelty seeking, and consumer creativity. Journal of Consumer Research, Л3), 283-295.

Hoffmann, S., \& Soyez, K. (2010). A cognitive model to predict domain-specific consumer innovativeness. Journal of Business Research, 63(7), 778-785.

Hong, E. J., Cho, K. S., \& Choi, J. H. (2017). Effects of Anthropomorphic Conversational Interface for Smart Home: An Experimental Study on the Voice and Chatting Interactions. Journal of the $\mathrm{HCl}$ Society of Korea. 12(1), $15-23$.

Jeong, H. S., \& Kim, U. Y. (2003). A Study on the Relationship between Consumer Innovativeness and Shape of Consideration Sets. Journal of Consumer Studies, 14(4), 45-72.

Jeong, T. G. (2017). A Study on the Influence of Characteristics of Fin-Tech System on Consumer Acceptance: Focused on Mobile Banking. (Master dissertation, Pusan National University). Retrieved May 10, 2019 from http://dcollection.pusan.ac.kr/public_resource/pdf/ 000000125273_20190515104715.pdf

Jung, G. J., Hwang, H. J., \& Song, I. A. (2015). Impact of Internal Marketing Factors on Technological Innovation and Perceived Service Quality in Telecommunications. Journal of Distribution Science, 13(6), 87-96.

Kaiser, S. B. (1985). Social psychology of clothing and personal adornment. London, England: Macmillan.

Kim, J. W., \& Kim, S. I. (2012). A study on the acceptance intention for smart phone by the innovation diffusion theory: Focused on smart phone non-users. Journal of Information Technology Services, 11(1), 15-37.

Kim, S. H., \& Rhee, Y. S. (2001). A Study on the Relationship between the Fashion Leadership and the Characteristics of the Shopping-related Behavior. Journal of the Korean Society of Clothing and Textiles, 251), 162-172.

Koh, A. R., \& Nam, M. W. (1998). A Study on the Clothing Behavior and Psychological Characteristics of Homosexual and Heterosexual Men. Journal of Korean Society of Clothing and Textiles, 22(4), 460-468.

Lee, C. M. (2017). The Effects of Functional Characteristics of Mobile Payments Services on Consumer Satisfaction Focus on TAM and IDT - (Master dissertation, Kyung Hee University). Retrieved May 5, 2019 from http://khu.dcollection.net/public_resource/pdf/200000068823_ 20190515103823.pdf

Midgley, D. F., \& Dowling, G. R. (1993). A longitudinal study of product form innovation: The interaction between predispositions and social messages. Journal of Consumer Research, 19(4), 611-625.

Min, S. J., Kim, H. J., \& Song, K. H. (2017). An Exploratory Study on Factors Influencing Chatbot Adoption by using the UTAUT Model. Journal of Korea Technology Innovation Society, 20175), 623-643.

Ostlund, L. E. (1974). Perceived innovation attributes as predictors of innovativeness. Journal of consumer research, 1(2), 23-29.

Park, K. A. (1999). The Effects of Perceived Innovation Attributes on Fashion Innovation Behavior. Journal of Korean Society of Clothing and Textiles, 24(3), 393-400.

Park, M. S. (2017). The influence of factors such as personal innovativeness, self-efficacy and perceived playfulness on messenger platform chatbot service to use more: Focusing on the ETAM. (Master dissertation, Hongik University). Retrieved October 26, 2017 from http://moonjeong.hongik.ac.kr/search/detail/CATTOT0000019 79943

Park, Y. B., \& Park, H. J., (2017). Testing for Use and Acceptance of Internet Banking Based on UTAUT Model. Journal of the Korea Industrial Information Systems Research, 22(1), 11-21.

Rogers, E. M. (1962). Diffusion of Innovations (1st ed.). New York, NY: The Free Press.

Rogers, E. M. (1995). Lessons for guidelines from the diffusion of innovations. Joint Commission Journal on Quality and Patient Safety, 21(7), 324-328.

Rogers, E. M., \& Shoemaker, F. F. (1971). Communication of Innovations; A Cross-Cultural Approach.

Seo, D. S. (2015). E-Strategy between European and Korean Innovative Business Channels in Post-New Normal Era. East Asian Journal of Business Management, 5(4), 59-66.

Shin, H. S. (2013). A Study on Acceptance Intention of Domestic Dental Low Handpiece Based on Innovation Diffusion Theory. (Master dissertation, Soongsil University). Retrieved May 8, 2019 from hhttp://oasis.dcollection.net /public_resource/pdf/000001561452_20190515112524.pdf

Veryzer, R. W. Jr. (1998). Key factors affecting customer evaluation of discontinuous new products. Journal of Product Innovation Management, 15(2), 136-150.

Yang, J. H. (2005). A Study on Fashion Leadership and Clothing Interest according to Sex Role Identify of Male College Students. (Master dissertation, Ewha Womans University). Retrieved May 10, 2019 from http://dcollection.ewha.ac.kr/public_resource/pdf/0000000123 42_20190515110437.pdf

Yoo, I. M. (2011). An Empirical Study in Innovation Diffusion Process of Intelligent Home Network Characteristics Influencing User's Resistance and Adoption: Focus on the 
Moderating Effect in User's level of Knowledge and Adoption Stage. (Ph.D dissertation, Kyung Hee University).
Retrieved May 5, 2019 from http://khu.dcollection.net/public _resource/pdf/200000053547_20190515101218.pdf 